\title{
Prevalence and correlates of diabetic nephropathy in patients with youth onset diabetes in India
}

\author{
P A Praveen ${ }^{1}$, A Amutha ${ }^{2}$, K Singh ${ }^{3}$, U Shankar1, T Kaur ${ }^{4}$, \\ RS Dhaliwal', A K Das ${ }^{5}$, C S Yajnik6, V Mohan², Nikhil Tandon'
}

${ }^{1}$ All India Institute of Medical Sciences, New Delhi, India, ${ }^{2}$ Madras Diabetes Research Foundation, Chennai, India, ${ }^{3}$ Public Health Foundation of India, New Delhi, India, ${ }^{4}$ Indian Council of Medical Research, New Delhi, India, ${ }^{5}$ Pondicherry institute of Medical Sciences, Puducherry, India,

${ }^{6}$ King Edward Memorial Hospital and Research Centre, Pune, India

\section{Background}

With the rising prevalence of diabetes in youth, an increase in diabetes-related complications, such as nephropathy, is anticipated. However, data on the epidemiology of diabetic nephropathy in youth onset diabetes are limited.

\section{Objectives}

* To compare the prevalence of diabetic nephropathy among patients with young onset Type 1 (T1DM) and Type 2 diabetes (T2DM).

* To identify the risk factors of diabetic nephropathy among youth onset T1DM and T2DM patients.

\section{Methods}

* The study population was selected from a multi city, multicentric clinic based registry of youth onset diabetes-YDR in India. Data from each clinic (reporting centre) were collated by the designated collaborating centre in that city.

- Data of all patients with youth onset (age at diagnosis $\leq 25$ years) T1DM $(n=2167)$ and T2DM $(n=857)$, registered (from 2000 to 2012) at the Delhi (North India) and Chennai (South India) collaborating centres of the above registry were analysed.

* Diabetes was classified using symptom-based clinical criteria.

* Patients were labeled to have diabetic nephropathy if 24 hour urine protein excretion was greater than $500 \mathrm{mg}$ or urine albumin excretion greater than $300 \mathrm{mg}$.

\section{Results}

* Prevalence (95\% C.I) of diabetic nephropathy was higher among patients with type 2 diabetes $[6.4 \%(4.8,8.1)]$ compared to type 1 diabetes $[3.0 \%(2.3,3.8)]$.

* The mean duration of diabetes since diagnosis (95\% C.I) was significantly higher among those with nephropathy [Type 1 diabetes- 11.0 (8.7, 13.2); Type 2 diabetes-12.3 (9.4, 15.3)] compared to those without nephropathy [Type 1 diabetes- 3.0 $(2.7,3.2)$; Type 2 diabetes- $5.7(5.1,6.2)]$.

* In multivariable logistic regression analysis, factors such as duration of diabetes and blood pressure were independently positively associated with diabetic nephropathy in both type 1 and type 2 diabetes (Tables $1 \& 2$ ).

* However, factors such as obesity and HbA1c did not show any association with the presence of diabetic nephropathy.

* The prevalence of diabetic retinopathy increased with age (Figure-1). However, there was no gender difference in the prevalence of diabetic nephropathy in both type 1 and type 2 diabetes

\section{Figure-1: Age specific prevalence of diabetic nephropathy}

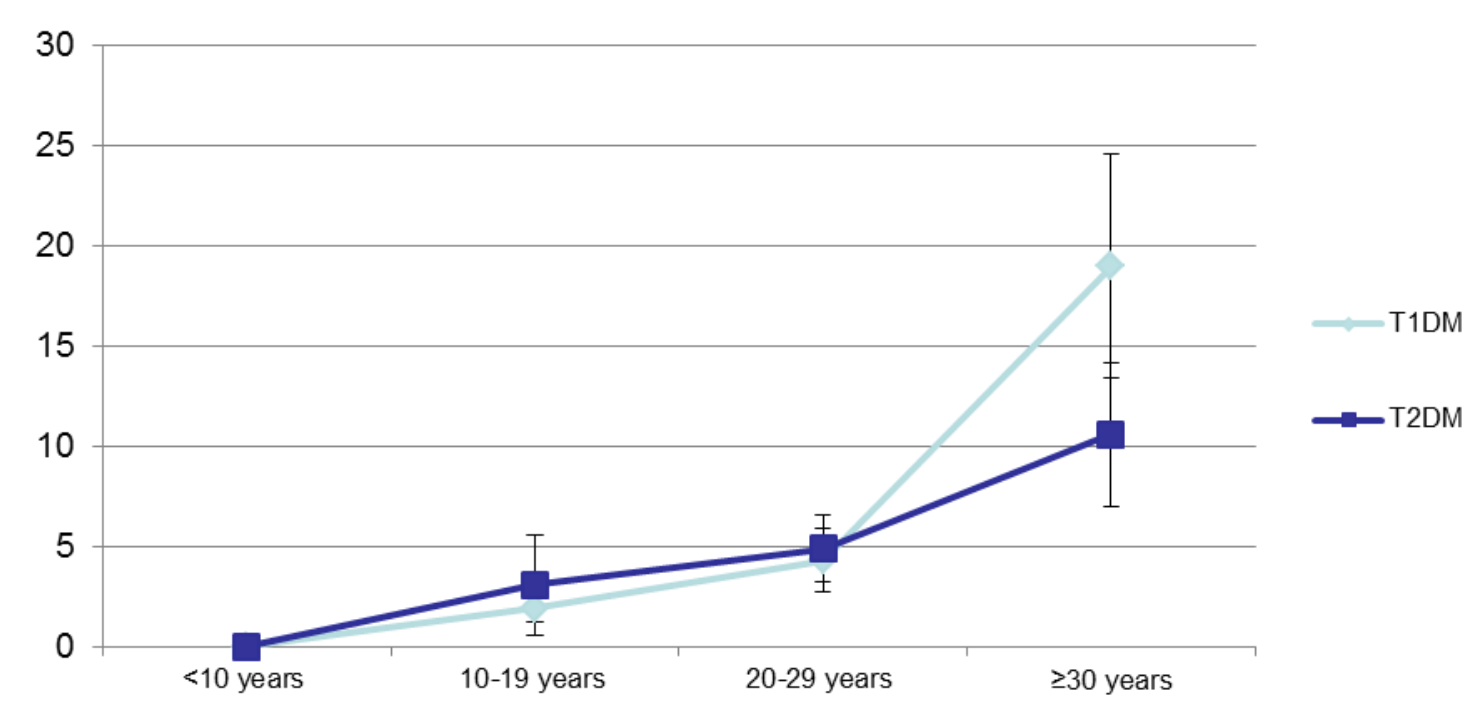

Table -1: Risk factors of diabetic nephropathy among T1DM

\begin{tabular}{|l|c|c|}
\hline \multicolumn{1}{|c|}{ Factors } & Adjusted odds ratio (95\% Cl) & P value \\
\hline Age at diagnosis & Ref & \\
\hline$<10 \mathrm{y}$ & $1.02(0.50,2.07)$ & 0.96 \\
\hline $\mathbf{1 0 - 1 9} \mathrm{y}$ & $2.13(0.90,5.04)$ & 0.09 \\
\hline $\mathbf{2 0 - 2 5} \mathrm{y}$ & Ref & \\
\hline Duration of diabetes since diagnosis & $2.20(0.83,5.79)$ & 0.116 \\
\hline$<5 \mathrm{y}$ & $8.39(4.10,17.20)$ & $<0.0001$ \\
\hline $\mathbf{5 - 9} \mathrm{y}$ & Ref & \\
\hline$\geq 10 \mathrm{y}$ & $0.58(0.21,1.64)$ & 0.30 \\
\hline Body Mass Index & $1.07(0.50,2.28)$ & 0.85 \\
\hline Normal & Ref & \\
\hline Underweight & $6.94(3.61,13.32)$ & $<0.0001$ \\
\hline Overweight/obese & & \\
\hline Raised blood pressure & & \\
\hline No & & \\
\hline Yes & &
\end{tabular}

Table -2: Risk factors of diabetic nephropathy among T2DM

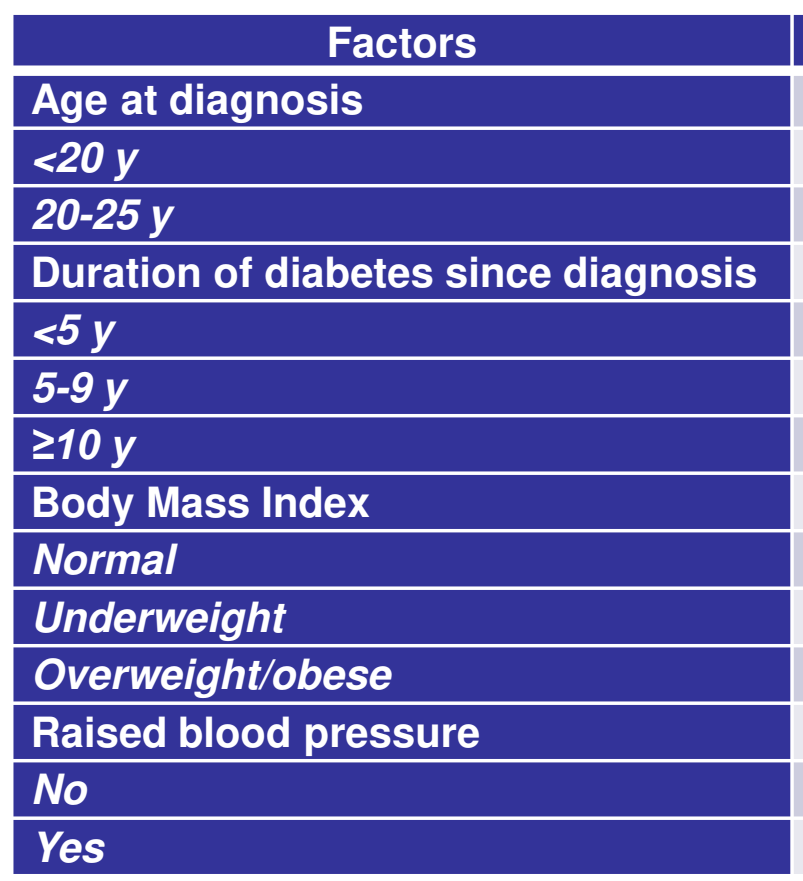
Adjusted odds ratio $(95 \% \mathrm{Cl})$

P value

Ref

$0.71(0.39,1.29)$

0.26

$0.87(0.28$,

$3.83(2.10,7.12)$

0.81

$<0.0001$

Ref

$2.53(0.48,13.14)$

$0.98(0.53,1.79)$

0.27

Ref

$2.07(1.15,3.71)$

0.01

\section{Conclusions}

* Despite short duration of disease, there was a considerable burden of diabetic nephropathy among patients with youth onset diabetes in India, regardless of the diabetes type.

* This warrants early screening for diabetes complication in patients with youth onset diabetes.
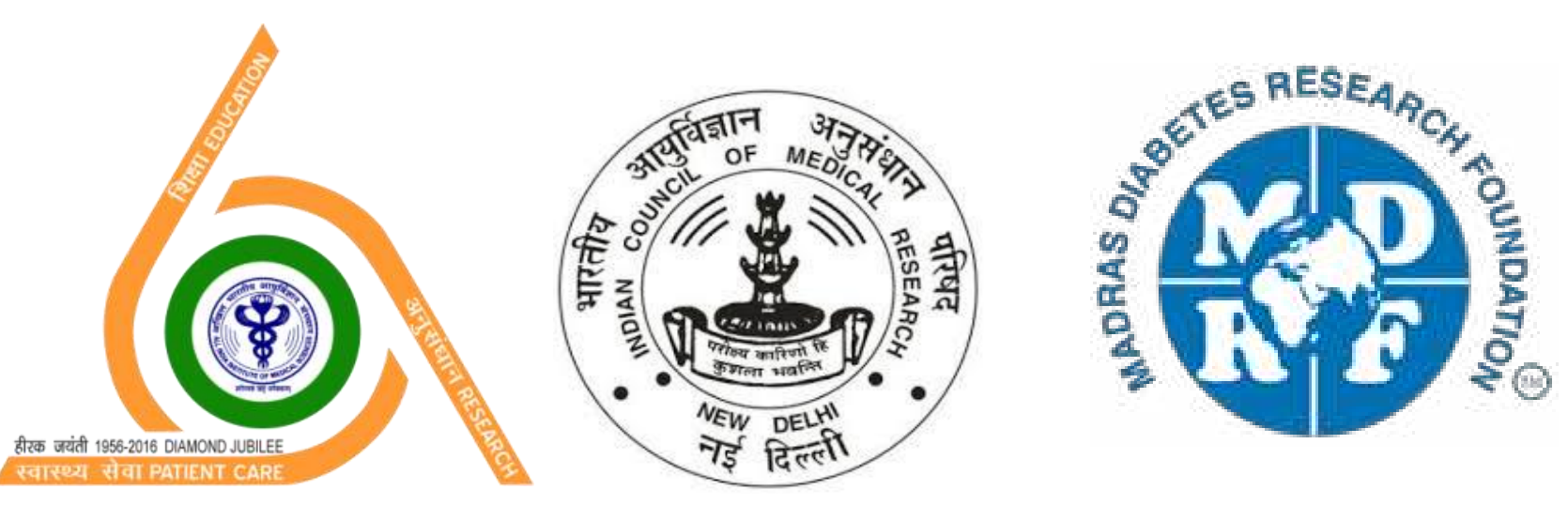